\title{
Calcium- and Otoferlin-Dependent Exocytosis by Immature Outer Hair Cells
}

\author{
Maryline Beurg, ${ }^{1}$ Saaid Safieddine, ${ }^{2}$ Isabelle Roux, ${ }^{2}$ Yohan Bouleau, ${ }^{1}$ Christine Petit, ${ }^{2}$ and Didier Dulon ${ }^{1}$ \\ ${ }^{1}$ Equipe Neurophysiologie de la Synapse Auditive, Equipe Mixte de Recherche, Inserm U587 et Université Victor Segalen, Institut des Neurosciences de \\ Bordeaux, Centre Hospitalier Universitaire Pellegrin, 33076 Bordeaux, France, and 2Unité de Génétique et Physiologie de l'audition, Unité Mixte de \\ Recherche, Inserm U587 et Université Pierre et Marie Curie, Collège de France, Institut Pasteur, 75015 Paris, France
}

Immature cochlear outer hair cells ( $\mathrm{OHCs}$ ) make transient synaptic contacts (ribbon synapses) with type I afferent nerve fibers, but direct evidence of synaptic vesicle exocytosis is still missing. We thus investigated calcium-dependent exocytosis in murine OHCs at postnatal day 2 (P2)-P3, a developmental stage when calcium current maximum amplitude was the highest. By using time-resolved patch-clamp capacitance measurements, we show that voltage step activation of L-type calcium channels triggers fast membrane capacitance increase. Capacitance increase displayed two kinetic components, which are likely to reflect two functionally distinct pools of synaptic vesicles, a readily releasable pool (RRP; $\tau=79 \mathrm{~ms}$ ) and a slowly releasable pool $(\tau=870 \mathrm{~ms})$. The RRP size and maximal release rate were estimated at $\sim 1200$ vesicles and $\sim 15,000$ vesicles/s, respectively. In addition, we found a linear relationship between capacitance increase and calcium influx, like in mature inner hair cells (IHCs). These results give strong support to the existence of efficient calcium-dependent neurotransmitter release in immature OHCs. Moreover, we show that immature OHCs, just like immature IHCs, are able to produce regenerative calcium-dependent action potentials that could trigger synaptic exocytosis in vivo. Finally, the evoked membrane capacitance increases were abolished in $\mathrm{P} 2-\mathrm{P} 3 \mathrm{OHCs}$ from mutant $\mathrm{Otof}^{-/-}$mice defective for otoferlin, despite normal calcium currents. We conclude that otoferlin, the putative major calcium sensor at IHC ribbon synapses, is essential to synaptic exocytosis in immature OHCs too.

Key words: cochlea; organ of Corti; outer hair cells; ribbon synapses; exocytosis; otoferlin

\section{Introduction}

The sense of hearing depends on fast, graded neurotransmitter release at the ribbon synapses of cochlear inner hair cells (IHCs) (for review, see Fuchs, 2005). The finely tuned and high-rate neurotransmitter release at IHC synapses involves synaptic vesicle fusion with the plasma membrane, which is precisely controlled by calcium influx through L-type $\left(\mathrm{Ca}_{\mathrm{v}} 1.3\right)$ calcium channels (Brandt et al., 2003, 2005; Johnson et al., 2005). The molecular events that trigger synaptic exocytosis in IHCs are still poorly understood. These cells apparently lack some major proteins found at CNS synapses, including the calcium sensor synaptotagmin I (Safieddine and Wenthold, 1999). Otoferlin, a large synaptic vesicle transmembrane protein with six C2 domains, has been proposed to be the major calcium sensor at the IHC ribbon synapse (Roux et al., 2006). Otoferlin indeed interacts with the SNARE (soluble $N$-ethylmaleimide-sensitive factor attachment protein receptor) proteins, syntaxin-1 and synaptosome-

\footnotetext{
Received July 21, 2007; revised Dec. 27, 2007; accepted Dec. 27, 2007.

This work was supported by grants from the European Commission FP6 Integrated Project EuroHear (LSHG-CT2004-512063) and the French National Research Agency (ANR-07-Neuro-036-01). We thank Stuart Johnson and Walter Marcotti for their technical advice on the Optopatch, Frank Schmitz for providing us with the antibody to ribeye, and Jean-Pierre Hardelin for critical reading of this manuscript.

Correspondence should be addressed to Christine Petit or Didier Dulon, Inserm Unité Mixte de Recherche U587, Institut Pasteur, 25 rue du Dr Roux, 75724 Paris Cedex 15, France. E-mail: cpetit@pasteur.fr or dulon@bordeaux.inserm.fr.

DOI:10.1523/JNEUROSCI.4653-07.2008

Copyright $\odot 2008$ Society for Neuroscience $\quad$ 0270-6474/08/281798-06\$15.00/0
}

associated protein of $25 \mathrm{kDa}$ (SNAP-25), in a calcium-dependent way. Furthermore, in deaf mice carrying null otoferlin alleles (Otof ${ }^{-1-}$ mice), IHCs lack calcium-evoked-exocytosis (Roux et al., 2006).

In contrast to IHCs, outer hair cells (OHCs) do not significantly contribute to the afferent signaling, but rather act as sound signal amplifiers in the mature cochlea (for review, see Dallos et al., 2006). In immature OHCs, however, otoferlin is present during the first postnatal days in the mouse (Roux et al., 2006; Schug et al., 2006). At this stage, OHCs are contacted by type-I afferent nerve fibers (Pujol, 1985; Echteler, 1992; Huang et al., 2007) that bear glutamate receptors (Knipper et al., 1997; Engel et al., 2006), and they have presynaptic ribbon structures (Sobkowicz et al., 1982), which suggests that transient synaptic exocytosis takes place in these cells. In addition, immature OHCs express $\mathrm{Ca}_{\mathrm{v}} 1.3$ calcium currents (Michna et al., 2003) that resemble those controlling synaptic exocytosis in mature IHCs. Notably, Knirsch et al. (2007) have found that $\mathrm{Ca}_{\mathrm{v}} 1.3$ channels persist in a subpopulation of mature OHCs located at the cochlear apical end. These cells still have presynaptic ribbons and afferent type-I fibers $(\mathrm{Pu}-$ jol et al., 1997), and they express syntaxin-1 and SNAP-25 (Safieddine and Wenthold, 1999) as well as otoferlin (Roux et al., 2006), suggesting that they too undergo calcium-dependent synaptic exocytosis. The existence of calcium-dependent synaptic exocytosis, however, has so far not been demonstrated in mature or immature OHCs. 

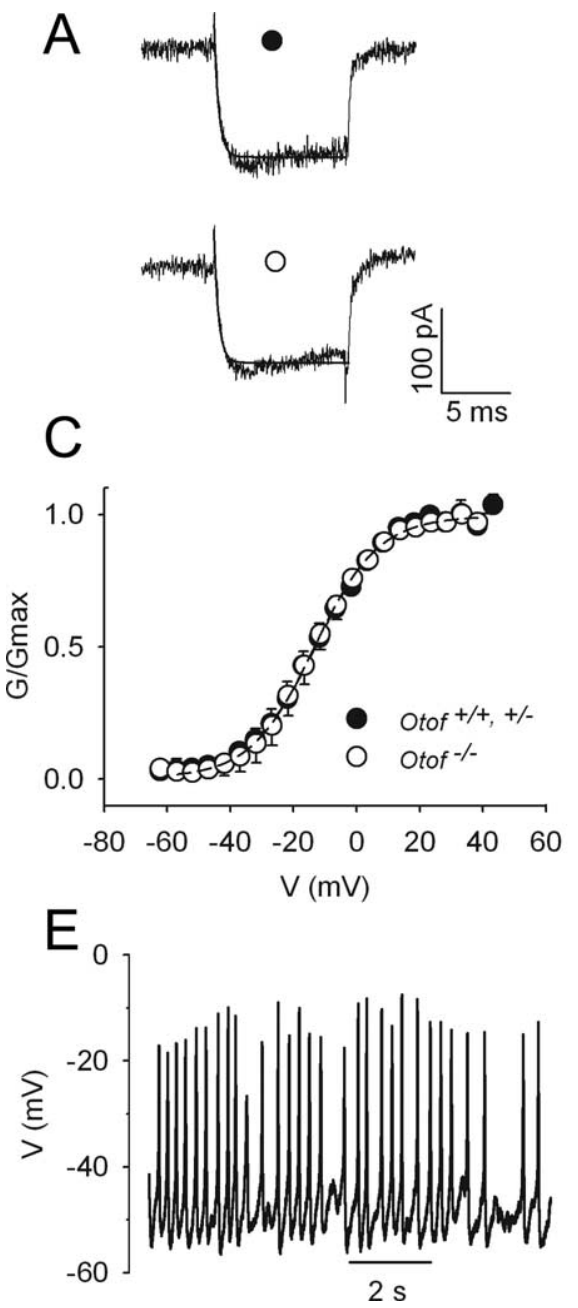

organ of Corti were double stained for otoferlin and ribeye using a monoclonal antibody $(1 / 500)$ and a polyclonal antibody (1/500), respectively.

Whole-cell recordings. Experiments were performed on mouse IHCs and OHCs from isolated organ of Corti apical coils, ranging from P1 to P10. Extracellular solution contained the following (in mM): $115 \mathrm{NaCl}, 6 \mathrm{KCl}, 10 \mathrm{CaCl}_{2}$, 30 TEA, $2 \mathrm{Na}$ pyruvate, 8 glucose, and $10 \mathrm{Na}-$ HEPES, pH 7.4. Tetrodotoxin $(1 \mu \mathrm{M})$, apamin $(1 \mu \mathrm{M})$, and XE-991 (1 $\mu \mathrm{M})$ (Sigma-Aldrich, St. Quentin Fallavier, France) were added to the extracellular solution to block $\mathrm{Na}^{+}$and $\mathrm{K}^{+}$ conductances. Because we worked at room temperature (RT; $22-24^{\circ} \mathrm{C}$ ), we used, unless otherwise specified, $10 \mathrm{~mm} \mathrm{CaCl}_{2}$ in the extracellular solution to increase the calcium current $\left(I_{\mathrm{Ca}}\right)$. Recording pipette solution contained the following (in mM): 130 Cs-gluconate, $1 \mathrm{MgCl}_{2}$, $5 \mathrm{Na}_{2}$ ATP, $0.5 \mathrm{Na}_{2} \mathrm{GTP}, 5$ TEA, 1 EGTA, and 10 Cs-HEPES, pH 7.2. Spontaneous action potentials (APs), however, were recorded using a potassium-based intracellular solution (in mM: $135 \mathrm{KCl}, 0.1 \mathrm{CaCl}_{2}, 1.5 \mathrm{MgCl}_{2}, 11$ EGTA, 5 HEPES, and $2.5 \mathrm{Na}_{2} \mathrm{ATP}, \mathrm{pH}$ 7.4) and the above-described extracellular solution with no pharmacological blocker.

Capacitance measurement. Changes in cell membrane capacitance $\left(\Delta C_{\mathrm{m}}\right)$ were used to monitor fusion of vesicles with the plasma membrane during exocytosis, and measured using the tracking circuitry of an Optopatch amplifier as described by Johnson et al. (2002) (for details, see supplemental material, available at www.jneurosci.org).

Data analysis. Curve fitting and analysis were done using Origin software (OriginLab, Northampton, MA) (see supplemental material, available at www.jneurosci.org). The criterion for statistical significance was chosen to be $p<0.05$ and evaluated by Student's $t$ tests. Variability is reported as \pm SEM.

\section{Results}

Calcium currents and spontaneous action potentials in immature $\mathrm{OHCs}$ Neonatal OHCs displayed rapidly activating $I_{\mathrm{Ca}}$ in response to depolarizing voltage steps (Fig. 1A). Analysis of the calcium currentvoltage relationship indicated that $I_{\mathrm{Ca}}$ acti-

Using cell membrane capacitance measurements, we report that calcium-dependent exocytosis actually occurs in immature OHCs. Moreover, we found that this exocytosis was absent in OHCs from otoferlin-deficient mice. Finally, we were able to record spontaneous, calcium-dependent action potentials in immature OHCs, which may account for synaptic vesicle release in vivo.

\section{Materials and Methods}

Animals. Experiments were performed on mice obtained by interbreeding of Otof ${ }^{+/-}$mice (Roux et al., 2006). The overall study was performed on 66 mice (15 Otof ${ }^{+/+}, 32 \mathrm{Otof}^{+/-}$, and $19 \mathrm{Otof}^{-/-}$) issued from 36 different litters. All experiments were performed in accordance with the European Community Council Directive 86/609/EEC.

Immunohistofluorescence. Tissue processing, immunohistofluorescence, and confocal imaging were performed as described previously (Roux et al., 2006). Whole-mount preparations of postnatal day 3 (P3) vates near $-40 \mathrm{mV}$ and reaches a maximum at $+5 \mathrm{mV}$ (Fig. $1 B$ ). $I_{\mathrm{Ca}}$ was not significantly different between $\mathrm{Otof}^{+/+}$and $\mathrm{Otof}^{+/-}\left(I_{\max }=\right.$ $100.1 \pm 7.0 \mathrm{pA} ; n=11)$ and $\operatorname{Otof}^{--}\left(I_{\max }=114.8 \pm 7.5 \mathrm{pA} ; n=9\right)$ OHCs. Normalized conductance-voltage curves also gave indistinguishable parameters $\left(G_{\max }, V_{1 / 2}\right.$, and $\left.k\right)$ between $\mathrm{Otof}^{+/+}$and Otof $^{+/-}\left(G_{\max }=2.6 \pm 0.4 \mathrm{nS} ; V_{1 / 2}=-12.2 \pm 0.5 \mathrm{mV} ; k=10.1 \pm\right.$ $0.4 \mathrm{mV})$ and Otof $^{-1-}\left(G_{\max }=3.0 \pm 0.2 \mathrm{nS} ; V_{1 / 2}=-12.3 \pm 0.5 \mathrm{mV}\right.$; $k=9.9 \pm 0.5 \mathrm{mV}$ ) cells when fitted with a first-order Boltzmann equation (Fig. 1C). The mean cell capacitance was not significantly different between P2-P3 $\mathrm{Otof}^{+/+}$and $\mathrm{Otof}^{+/-} \mathrm{OHCs}(6.0 \pm 0.2 \mathrm{pF}$; $n=50)$ and P2-P3 Otof ${ }^{-1-}$ OHCs $(5.9 \pm 0.2 \mathrm{pF} ; n=20)$ either. In $\mathrm{Otof}^{+/+}$and $\mathrm{Otof}^{+/-} \mathrm{OHCs}$, the calcium current density was maximal between P2 and P5, and drastically decreased after P8 (Fig. 1D). This result is in good agreement with previous studies by Michna et al. (2003) and Knirsch et al. (2007). A similar large decrease of $I_{\mathrm{Ca}}$ 
occurred in Otof ${ }^{-1}$ OHCs between P2-P3 $(n=29)$ and P10 $(n=4)$ (data not shown).

Regenerative APs could be recorded in all P3 OHCs studied, in $10 \mathrm{~mm}$ extracellular calcium (five Otof ${ }^{+/+}$and Otof ${ }^{+/-}$and three Otof ${ }^{-1}$ OHCs). Spontaneous AP firing was observed without injecting current, from a mean resting membrane potential of $-50 \pm 1 \mathrm{mV}$ (range, -46 to -56 $\mathrm{mV} ; n=8)$. Spontaneous APs occurred at a mean frequency of $1.7 \pm 0.6 \mathrm{~Hz}$, and had a maximum peak amplitude of $33 \pm 4 \mathrm{mV}$ and a mean half-width of $29 \pm 6 \mathrm{~ms}$ (Fig. $1 E, F)$. Similar AP firing was also recorded in five additional P3 (Otof ${ }^{+/-}$) OHCs in artificial perilymph containing $1.3 \mathrm{~mm}$ $\mathrm{CaCl}_{2}$ at near-physiological temperature $\left(34 \pm 2^{\circ} \mathrm{C}\right)$. These APs are likely to be driven by calcium currents, because they were insensitive to tetrodotoxin, and were blocked by $50 \mu \mathrm{M}$ of the L-type calcium channel antagonist nifedipine. Moreover, APs were not observed in P9 OHCs $(n=4$; data not shown), when only very low $I_{\mathrm{Ca}}$ could be recorded (Fig. 1D). These results are consistent with a previous report by Marcotti and Kros (1999), showing voltage responses to current injection that suggested regenerative APs in neonatal mouse OHCs.

\section{Calcium-dependent synaptic exocytosis}

To demonstrate calcium-dependent exocytosis in OHCs, we recorded $\Delta C_{\mathrm{m}}$ during voltage-step activation of $I_{\mathrm{Ca}}$. We used P2-P3 immature OHCs to avoid the prestin electromotility contribution to cell membrane capacitance variation (Abe et al., 2007). Indeed, fast and reversible nonlinear capacitance changes caused by the voltage activation of prestin were absent in apical OHCs before P4 (data not shown).

At P2-P3, OHCs display large $I_{\mathrm{Ca}}$ (Fig. $1 D$ ). Calcium entry induced by a $100 \mathrm{~ms}$ voltage step from -80 to $0 \mathrm{mV}$ produced a mean $\Delta C_{\mathrm{m}}$ of $34.5 \pm 7.3 \mathrm{fF}\left(n=33,8 \mathrm{Otof}^{+/+}\right.$and $25 \mathrm{Otof}^{+/-}$ OHCs). An example of $C_{\mathrm{m}}$ recording is shown in Fig. $2 A$. The $C_{\mathrm{m}}$ jump was immediate, and the maximum value was already reached at the end of the $100 \mathrm{~ms}$ depolarizing step. The $C_{\mathrm{m}}$ increase was sustained over a period of several hundred milliseconds after the end of the stimulation. Analysis of the $\Delta C_{\mathrm{m}}$-voltage relationship showed a positive correlation between $\Delta C_{\mathrm{m}}$ and $I_{\mathrm{Ca}}$ amplitude (Fig. $2 \mathrm{~B}$ ). To verify that exocytosis was indeed triggered by a rise in intracellular calcium concentration, some $\mathrm{OHCs}$ were recorded using an intrapipette solution containing $10 \mathrm{~mm}$ of the fast $\mathrm{Ca}^{2+}$-chelator BAPTA (instead of $1 \mathrm{~mm} \mathrm{EGTA).}$ In the $10 \mathrm{~mm}$ BAPTA condition, OHCs, while showing a large peak $I_{\mathrm{Ca}}$ of $67 \pm 5.3 \mathrm{pA}$, only showed very small $C_{\mathrm{m}}$ responses, averaging $2.2 \pm 0.8 \mathrm{fF}\left(n=6,2 \mathrm{Otof}^{+/+}\right.$and $\left.4 \mathrm{Otof}^{+/-}\right)$, to cell depolarization. In addition, $\Delta C_{\mathrm{m}}$ responses, recorded in the EGTA condition, were completely abolished when $I_{\mathrm{Ca}}$ was blocked by nifedipine ( $50 \mu \mathrm{M})$ ( $n=5$ cells; data not shown). Together, these results give evidence of synaptic exocytosis in immature OHCs and the involvement of L-type calcium channels
B
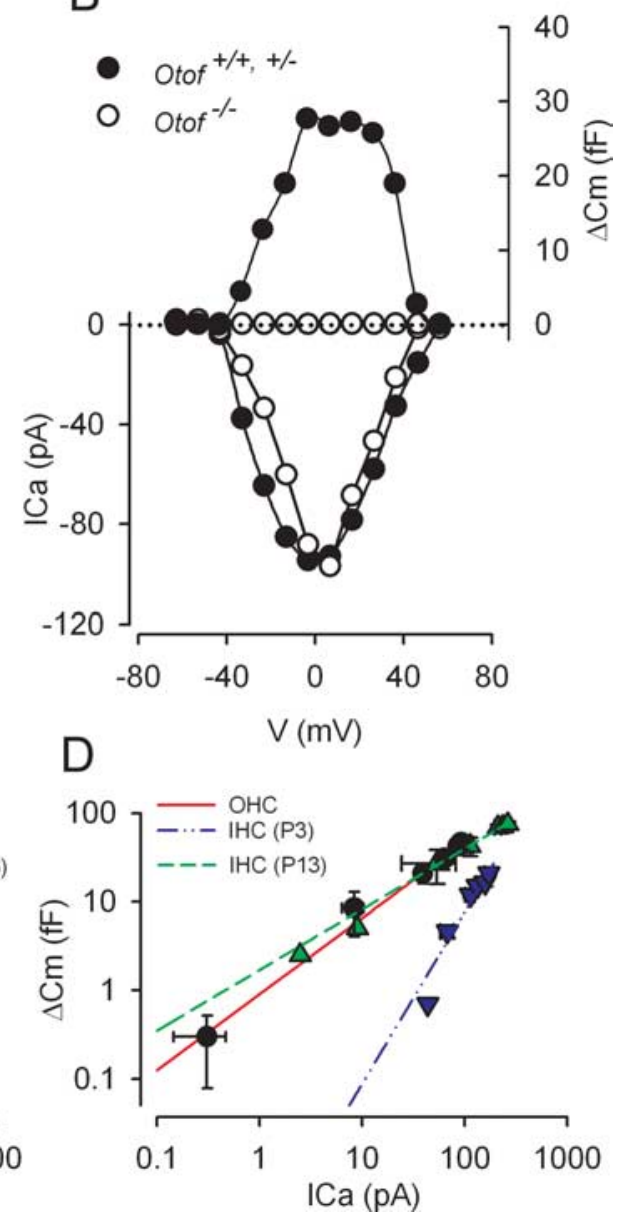

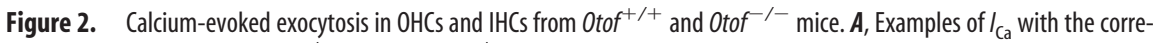
sponding $\Delta C_{\mathrm{m}}$ response in $\mathrm{Otof}^{+/-}()_{1}$ and $\mathrm{Otof}^{-1-}\left(\mathrm{O}^{-} \mathrm{OHCs}\right.$ at P2. Cells were stimulated by a $100 \mathrm{~ms}$ voltage step from a holding potential of -82 to $0 \mathrm{mV}$. $\boldsymbol{B}$, Voltage- $I_{\mathrm{Ca}}$ relationship (bottom) and corresponding $\Delta C_{\mathrm{m}}$ (top) are shown for the same (t) $0 \mathrm{mV}$, in $10 \mathrm{mV}$ increments (100 ms step duration). $\Delta C_{\mathrm{m}}$ was plotted against corresponding $I_{\mathrm{Ca}}$. The synaptic transfer function was best fitted with a power function $Y=a X^{N}$, with $a=1,0.002$, and 1.3 and $N=0.84,1.9$, and 0.68 in P2-P3 $\mathrm{OHCS}, \mathrm{P} 3 \mathrm{IHCs}$, and P13 $\mathrm{HHC}$, respectively. $D, I_{\mathrm{Ca}_{\mathrm{a}}}$ dependence of $\Delta C_{\mathrm{m}}$ as in $C$ but plotted in double-logarithmic scales.

in this process. Increases in $C_{\mathrm{m}}$ and $I_{\mathrm{Ca}}$ could also be recorded in more physiological conditions at $34 \pm 2^{\circ} \mathrm{C}$ with $1.3 \mathrm{~mm}$ external $\mathrm{CaCl}_{2}$ (data not shown). A calcium efficiency (ratio $\Delta C_{\mathrm{m}} / I_{\mathrm{Ca}}$ (peak)) of $0.35 \mathrm{fF} / \mathrm{pA}(n=3)$ was recorded in these conditions. This value is similar to the efficiency we recorded in the $10 \mathrm{~mm}$ $\mathrm{CaCl}_{2}$ condition, at RT $(0.31 \mathrm{fF} / \mathrm{pA} ; n=33)$.

To further characterize the calcium-dependent exocytosis in immature OHCs, we studied the relationship between calcium inflow and exocytosis, i.e., the synaptic transfer function. P2-P3 $\mathrm{OHCs}$ were stimulated by a $100 \mathrm{~ms}$ voltage step to a range of potentials varying between -50 and $0 \mathrm{mV}$, and $\Delta C_{\mathrm{m}}$ responses were plotted against corresponding $I_{\mathrm{Ca}}$ amplitudes. Peak $I_{\mathrm{Ca}}$ was preferred to $I_{\mathrm{Ca}}$ integral (total amount of calcium charges) because of the frequent presence of a residual outward potassium current carried by SK channels incompletely blocked by apamin. The relationship between $\Delta C_{\mathrm{m}}$ and $I_{\mathrm{Ca}}$ was best fitted by using a power function, with $N=0.84$ (Fig. $2 C$ ). For comparison, the synaptic transfer function was also studied in P3 IHCs and "nearly mature" (P13) IHCs, in similar $10 \mathrm{~mm} \mathrm{CaCl}_{2}$ conditions (Fig. 2C,D). Interestingly, P2-P3 OHC exocytosis had a calcium efficiency similar to that of P13 IHCs $(0.30 \mathrm{fF} / \mathrm{pA}$ and power 


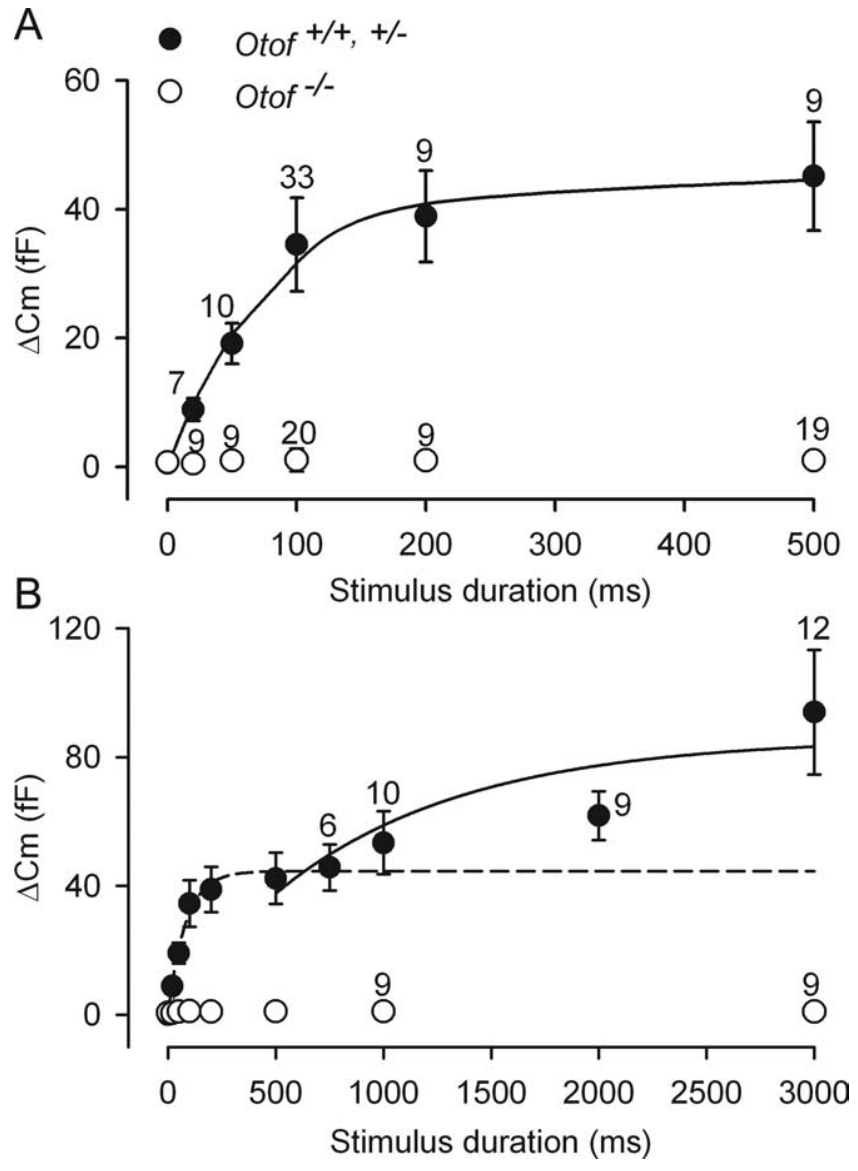

Figure 3. Kinetics of exocytosis in immature $0 H C s . A, B$, Average $\Delta C_{m}$ was plotted as a function of the voltage stimulus duration. All cells were voltage stepped to $0 \mathrm{mV}$ from a holding potential of $-82 \mathrm{mV} . \Delta C_{\mathrm{m}}$ was obtained in response to stimuli with varying durations, up to $500 \mathrm{~ms}(\boldsymbol{A})$ or $3000 \mathrm{~ms}(\boldsymbol{B})$. Solid lines correspond to two consecutive single-exponential fits, with $\tau=79.3 \mathrm{~ms}$ in $\boldsymbol{A}$, and $\tau=870 \mathrm{~ms}$ in $\boldsymbol{B}$, which define an RRP and an SRP of synaptic vesicles, respectively. In $\boldsymbol{B}$, the dashed line is extrapolated from the fit shown in $\boldsymbol{A}$. Numbers of tested P2-P3 0 HCs are indicated on the graphs.

function fitted with $N=0.7)$, whereas that of P3 IHCs was lower $(0.11 \mathrm{fF} / \mathrm{pA}$ and power function fitted with $N \sim 2)$.

\section{Kinetics of synaptic vesicle release}

We used voltage steps to $0 \mathrm{mV}$ with varying durations to study the kinetics of vesicle release in P2-P3 OHCs. This method has been used to show the existence of two different pools of vesicles in IHC synaptic exocytosis (Moser and Beutner, 2000; Beutner et al., 2001; Johnson et al., 2005). In these studies, two components of vesicular release have been observed. The fast $\Delta C_{\mathrm{m}}$ component, which can be recorded during brief stimuli $(<500 \mathrm{~ms})$, is believed to account for exocytosis of the ready releasable pool of vesicles (RRP), whereas the slower $\Delta C_{\mathrm{m}}$ component, which can be measured during longer depolarizations, would be caused by the release of a second pool of vesicles [slowly releasable pool (SRP)], located at a larger distance from the calcium entry site.

A fast exocytosis component was characterized in $\mathrm{P} 2-\mathrm{P} 3$ OHCs (Fig. 3A). Whereas short stimuli (5-10 ms) were unable to elicit $\Delta C_{\mathrm{m}}$ responses above the background noise (1.8 \pm 1.0 $\mathrm{fF})$, the amplitude of $\Delta C_{\mathrm{m}}$ responses rapidly increased with stimulus duration between 20 and $100 \mathrm{~ms}$, and reached a steady state value at $500 \mathrm{~ms}$. A single-exponential fit with a time constant of $79.3 \mathrm{~ms}$ and a maximal $\Delta C_{\mathrm{m}}$ of $44.5 \mathrm{fF}$ sug- gested that this fast exocytosis component involves a single RRP. Assuming a $\Delta C_{\mathrm{m}}$ of $37 \mathrm{aF}$ per vesicle (Lenzi et al., 1999), calculation gave a RRP of $\sim 1200$ vesicles in OHCs. This RRP could be released with a maximum rate of $\sim 15,100$ vesicles/s $(560 \mathrm{fF} / \mathrm{s})$. This value is similar to the release rate reported by Johnson et al. (2005) in P10-P20 mouse IHCs maintained at body temperature in physiological $(1.3 \mathrm{~mm})$ extracellular calcium (rate constant of $459 \mathrm{fF} / \mathrm{s}$ with $\tau=53 \mathrm{~ms}$ ). The RRP of immature OHCs, however, is significantly larger than the RRP reported in mature IHCs, i.e., 660 synaptic vesicles or less (Johnson et al., 2005). Intriguingly enough, hair cells from the frog saccule and the turtle auditory papilla have both larger RRP responses and faster kinetics of exocytosis (Edmonds et al., 2004; Schnee et al., 2005). This may suggest different mechanisms for synaptic vesicle fusion in lower vertebrates.

During longer stimulations, a second, slower exocytosis component (SRP) could be identified in neonatal P2-P3 OHCs. This component was also best fitted using a single exponential starting after $500 \mathrm{~ms}\left(\tau=870 \mathrm{~ms}\right.$; maximal $\Delta C_{\mathrm{m}}$ $=86 \mathrm{fF}$ ), giving a maximal release rate of $\sim 2670$ vesicles/s ( 99 $\mathrm{fF} / \mathrm{s}$ ) (Fig. $3 B$ ). Notably, the $C_{\mathrm{m}}$ responses over the entire time range (up to $3 \mathrm{~s}$ ) could not be accurately fitted with a double exponential. A good fit for the RRP and SRP was obtained using two sequential and independent single-exponential functions, which argues for a delayed activation of the second phase of exocytosis. The physiological significance of this secondary release, however, remains questionable because it was observed during nonphysiological long depolarization. Whether the SRP release also occurs at the ribbon synapses or involves other nonsynaptic release sites remains to be determined.

\section{Otoferlin is required for calcium-dependent exocytosis in immature OHCs}

At P3, otoferlin is abundant both in OHCs and IHCs (Roux et al., 2006). Otoferlin was detected throughout the cytoplasm, but the immunostaining was stronger in the basolateral membrane area, where the ribbon synapses are located (Fig. 4). Indeed, the otoferlin distribution largely overlapped with that of the integral ribbon protein ribeye (Schmitz et al., 2000) in both cell types (Fig. 4, top). We thus asked whether synaptic exocytosis in immature OHCs depends on the presence of otoferlin, by studying the $\Delta C_{\mathrm{m}}$ response to cell depolarization in P2-P3 Otof ${ }^{-1-}$ mice that lack otoferlin. In Otof ${ }^{-1-} \mathrm{OHCs}$, we found that the exocytosis response was abolished $\left(\Delta C_{\mathrm{m}}\right.$ responses below background threshold of $1.8 \mathrm{fF} ; n=20$ ) (Fig. $2 A, B$ ), despite $I_{\mathrm{Ca}}$ values similar to wild-type mice (maximum current density of $17.1 \pm 1.0 \mathrm{pA} / \mathrm{pF}$ in $\mathrm{Otof}^{-/-}$mice compared with $18.5 \pm 1.3 \mathrm{pA} / \mathrm{pF}$ in $\mathrm{Otof}^{+/-}$and Otof ${ }^{+/+}$mice) (Fig. $1 A-C)$ and apparent normal presynaptic active zone assembly, as suggested by the ribeye immunostaining (Fig. 4, bottom). Longer depolarizations (up to several seconds) that allow larger intracellular calcium increase (Beutner et al., 2001) were ineffective as well (Fig. $3 B$ ). We conclude that otoferlin is required for both RRP and SRP synaptic vesicle exocytosis in immature OHCs.

\section{Discussion}

Our results provide strong evidence for the existence of spontaneous calcium action potentials and synaptic exocytosis in P2-P3 mouse OHCs that recording of EPSCs will definitively establish. Interestingly, P2-P3 OHC exocytosis had a calcium efficiency similar to that of mature P13 IHCs, whereas that of 
immature P3 IHCs was three times lower. This is in good agreement with morphological studies at early postnatal stages, showing that $\mathrm{OHCs}$ contain more ribbons than IHCs (Sobkowicz et al., 1982). Johnson et al. (2005), using a physiological (1.3 mM) extracellular calcium condition, also found a lower efficiency of exocytosis in the developing IHCs maintained at body temperature. The almost linear, noncooperative relationship between $\Delta C_{\mathrm{m}}$ and $I_{\mathrm{Ca}}$ in mature P13 IHCs and P2-P3 OHCs suggests that exocytosis relies on a one-to-one relationship between calcium binding and vesicle fusion events. A similar calcium dependence of release has been found in hair cells from the turtle auditory papilla (power function fitted with $N=0.9$ ) (Schnee et al., 2005). Furthermore, by recording postsynaptic currents, Keen and Hudspeth (2006) and Goutman and Glowatzki (2007) also found a linear calcium dependence of transmitter release at the level of a single hair cell ribbon synapse. Interestingly, our results demonstrate that otoferlin, the putative calcium sensor at IHC ribbon synapses (Roux et al. 2006), is essential to synaptic exocytosis in immature OHCs too.

We propose that synaptic activity in the immature OHCs contributes to the spontaneous discharge activity recorded in spiral ganglion neurons before the onset of hearing (Jones et al., 2007). Although electrical spiking activity is not essential to the synapse formation (Verhage et al., 2000), it is well established as critically involved in the maturation of neuronal circuitry (for review, see Hua and Smith, 2004). Synchronized spontaneous rhythmic activity of neurotransmission has indeed an instructive role in the refinement of neuronal connections in the developing retina (Galli and Maffei, 1988; Torborg and Feller, 2005). We suggest that the spontaneous spiking activity of immature $\mathrm{OHC}$ ribbon synapses plays a similar role in the developing auditory system.

\section{References}

Abe T, Kakehata S, Kitani R, Maruya S, Navaratnam D, Santos-Sacchi J, Shinkawa H (2007) Developmental expression of the outer hair cell motor prestin in the mouse. J Membr Biol 215:49-56.

Beutner D, Voets T, Neher E, Moser T (2001) Calcium dependence of exocytosis and endocytosis at the cochlear inner hair cell afferent synapse. Neuron 29:681-690.

Brandt A, Striessnig J, Moser T (2003) CaV1.3 channels are essential for development and presynaptic activity of cochlear inner hair cells. J Neurosci 23:10832-10840.

Brandt A, Khimich D, Moser T (2005) Few CaV1.3 channels regulate the exocytosis of a synaptic vesicle at the hair cell ribbon synapse. J Neurosci 25:11577-11585.

Dallos P, Zheng J, Cheatham MA (2006) Prestin and the cochlear amplifier. J Physiol (Lond) 576:37-42.

Echteler SM (1992) Developmental segregation in the afferent projections to mammalian auditory hair cells. Proc Natl Acad Sci USA 89:6324-6327.

Edmonds BW, Gregory FD, Schweizer FE (2004) Evidence that fast exocytosis can be predominantly mediated by vesicles not docked at active zones in frog saccular hair cells. J Physiol (Lond) 560:439-450.

Engel J, Braig C, Ruttiger L, Kuhn S, Zimmermann U, Blin N, Sausbier M, Kalbacher H, Munkner S, Rohbock K, Ruth P, Winter H, Knipper M (2006) Two classes of outer hair cells along the tonotopic axis of the cochlea. Neuroscience 143:837-849.
Fuchs PA (2005) Time and intensity coding at the hair cell's ribbon synapse. J Physiol (Lond) 566:7-12.

Galli L, Maffei L (1988) Spontaneous impulse activity of rat retinal ganglion cells in prenatal life. Science 242:90-91.

Goutman JD, Glowatzki E (2007) Time course and calcium dependence of transmitter release at a single ribbon synapse. Proc Natl Acad Sci USA 104:16341-16346.

Hua JY, Smith SJ (2004) Neural activity and the dynamics of central nervous system development. Nat Neurosci 7:327-332.

Huang LC, Thorne PR, Housley GD, Montgomery JM (2007) Spatiotemporal definition of neurite outgrowth, refinement and retraction in the developing mouse cochlea. Development 134:2925-2933.

Johnson SL, Thomas MV, Kros CJ (2002) Membrane capacitance measurement using patch clamp with integrated self-balancing lock-in amplifier. Pflugers Arch 443:653-663.

Johnson SL, Marcotti W, Kros CJ (2005) Increase in efficiency and reduction in $\mathrm{Ca}^{2+}$ dependence of exocytosis during development of mouse inner hair cells. J Physiol (Lond) 563:177-191.

Jones TA, Leake PA, Snyder RL, Stakhovskaya O, Bonham B (2007) Spontaneous discharge patterns in cochlear spiral ganglion cells. J Neurophysiol 98:1898-1908.

Keen EC, Hudspeth AJ (2006) Transfer characteristics of the hair cell's afferent synapse. Proc Natl Acad Sci USA 103:5537-5542.

Knipper M, Kopschall I, Rohbock K, Kopke AK, Bonk I, Zimmermann U, Zenner H (1997) Transient expression of NMDA receptors during rearrangement of AMPA-receptor-expressing fibers in the developing inner ear. Cell Tissue Res 287:23-41.

Knirsch M, Brandt N, Braig C, Kuhn S, Hirt B, Münkner S, Knipper M, Engel J (2007) Persistence of Cav1.3 $\mathrm{Ca}^{2+}$ channels in mature outer hair cells supports outer hair cell afferent signaling. J Neurosci 27:6442-6451.

Lenzi D, Runyeon JW, Crum J, Ellisman MH, Roberts WM (1999) Synaptic vesicle populations in saccular hair cells reconstructed by electron tomography. J Neurosci 19:119-132.

Marcotti W, Kros CJ (1999) Developmental expression of the potassium current IK, $\mathrm{n}$ contributes to maturation of mouse outer hair cells. J Physiol (Lond) 520:653-660.

Michna M, Knirsch M, Hoda JC, Muenkner S, Langer P, Platzer J, Striessnig J, Engel J (2003) Cav1.3 (alpha1D) $\mathrm{Ca}^{2+}$ currents in neonatal outer hair cells of mice. J Physiol (Lond) 553:747-758.

Moser T, Beutner D (2000) Kinetics of exocytosis and endocytosis at the cochlear inner hair cell afferent synapse of the mouse. Proc Natl Acad Sci USA 97:883-888.

Pujol R (1985) Morphology, synaptology and electrophysiology of the developing cochlea. Acta Otolaryngol [Suppl] 421:5-9.

Pujol R, Lavigne-Rebillard M, Lenoir M (1997) Development of sensory and neural structures in the mammalian cochlea. In: Development of the 
auditory system, Springer handbook of auditory research (Rubel EW, Popper AN, Fay RR, eds), pp 146-192. New York: Springer.

Roux I, Safieddine S, Nouvian R, Grati M, Simmler MC, Bahloul A, Perfettini I, Le Gall M, Rostaing P, Hamard G, Triller A, Avan P, Moser T, Petit C (2006) Otoferlin, defective in a human deafness form, is essential for exocytosis at the auditory ribbon synapse. Cell 127:277-289.

Safieddine S, Wenthold RJ (1999) SNARE complex at the ribbon synapses of cochlear hair cells: analysis of synaptic vesicle- and synaptic membraneassociated proteins. Eur J Neurosci 11:803-812.

Schnee ME, Lawton DM, Furness DN, Benke TA, Ricci AJ (2005) Auditory hair cell-afferent fiber synapses are specialized to operate at their best frequencies. Neuron 47:243-254.

Schug N, Braig C, Zimmermann U, Engel J, Winter H, Ruth P, Blin N, Pfister M, Kalbacher H, Knipper M (2006) Differential expression of otoferlin in brain, vestibular system, immature and mature cochlea of the rat. Eur J Neurosci 24:3372-3380.

Schmitz F, Königstorfer A, Südhof TC (2000) RIBEYE, a component of synaptic ribbons: a protein's journey through evolution provides insight into synaptic ribbon function. Neuron 28:857-872.

Sobkowicz HM, Rose JE, Scott GE, Slapnick SM (1982) Ribbon synapses in the developing intact and cultured organ of Corti in the mouse. J Neurosci 2:942-957.

Torborg CL, Feller MB (2005) Spontaneous patterned retinal activity and the refinement of retinal projections. Prog Neurobiol 76:213-235.

Verhage M, Maia AS, Plomp JJ, Brussaard AB, Heeroma JH, Vermeer H, Toonen RF, Hammer RE, van den Berg TK, Missler M, Geuze HJ, Südhof TC (2000) Synaptic assembly of the brain in the absence of neurotransmitter secretion. Science 287:864-869. 